\title{
Stem retention and survival in revision of anatomical convertible shoulder arthroplasty to reverse arthroplasty: a Dutch registry study
}

Luuk M. A. Theelen', Ben Mory', Sharmila Venkatesan', Anneke Spekenbrink-Spooren², Loes Janssen and Frederik O. Lambers Heerspink ${ }^{1 *}$ (D)

\begin{abstract}
Background: Convertible stem designs allow for stem retention during revision from anatomical to reverse shoulder arthroplasty. In some cases conversion is not possible for example due to excessive soft tissue tensioning. In these cases a total revision is necessary. The primary aim of this Dutch registry study was to evaluate the unforeseen stem reversion percentages in revision of convertible anatomical shoulder arthroplasty to reverse shoulder arthroplasty.

Methods: Shoulder arthroplasties $(n=2834)$ performed between 2014 and 2016 registered in the Dutch Arthroplasty Registry were selected. In 2016 94\% of primary arthroplasties and 92\% of revision arthroplasties were registered in the database. Arthroplasties were selected on convertibility. Mean follow-up was 2.4 years. We analysed the number of revisions for convertible and non-convertible designs. Cases with obligatory revisions as periprosthetic joint infections, stem loosening and periprosthetic fractures were excluded. Kaplan-Meier analysis was used to calculate humeral stem survival. Multivariate cox-regression analysis was used to determine risk factors for stem revision.

Results: The majority of procedures (respectively 90.9 and $72.1 \%$ for the convertible and non-convertible group) concerned a conversion to reverse shoulder arthroplasty $(p=.02)$. In the convertible group, the stem was retained in 29 out of 40 patients (72.5\%). Overall implant survival was $94.5 \%$ after a mean follow-up of 2.4 years. Hemiartroplasty, fracture as primary indication, previous shoulder surgery and lower age were risk factors for revision.

Conclusions: Although convertible designs are gaining popularity due to their expected advantage in revision arthroplasty, surgeons should be aware that during a revision procedure in $27.5 \%$ of the patients an unforeseen stem revision is necessary.
\end{abstract}

Keywords: Stem retention, Survival, Revision, Anatomical convertible shoulder arthroplasty

* Correspondence: olambersheerspink@viecuri.nl

'Department of Orthopaedic Surgery, VieCuri Medical Center, Venlo, The Netherlands

Full list of author information is available at the end of the article

(c) The Author(s). 2021 Open Access This article is licensed under a Creative Commons Attribution 4.0 International License, which permits use, sharing, adaptation, distribution and reproduction in any medium or format, as long as you give appropriate credit to the original author(s) and the source, provide a link to the Creative Commons licence, and indicate if changes were made. The images or other third party material in this article are included in the article's Creative Commons licence, unless indicated otherwise in a credit line to the material. If material is not included in the article's Creative Commons licence and your intended use is not permitted by statutory regulation or exceeds the permitted use, you will need to obtain permission directly from the copyright holder. To view a copy of this licence, visit http://creativecommons.org/licenses/by/4.0/. The Creative Commons Public Domain Dedication waiver (http://creativecommons.org/publicdomain/zero/1.0/) applies to the data made available in this article, unless otherwise stated in a credit line to the data. 


\section{Background}

The number of shoulder arthroplasties performed has been steadily rising over the past decades [1-6]. With an increase in the number of primary arthroplasties, the number of revision procedures are rising as well. The most common reasons for revision of anatomical shoulder arthroplasties are periprosthetic joint infection, instability/dislocation, secondary rotator cuff insufficiency, or aseptic loosening [7]. In the past, conversion of an anatomical total shoulder arthroplasty to a reverse shoulder arthroplasty required removal of the stem. In $20-25 \%$ of the cases this is associated with a risk of humeral fractures, or a need for osteotomy of the humerus to remove a fixed cemented stem. This could result in extensive soft tissue damage [3, 6, 8-12]. Convertible stem systems were designed to retain the humeral stem and convert it to a reverse prosthesis more easily. This is claimed to result in a lower complication rate, shorter operation time, less blood loss and fewer reinterventions $[6,11,13-19]$. A well-known problem in these conversions is excessive soft tissue tensioning, therefore the shoulder stem cannot be retained, or it impairs range of motion, causing an unforeseen revision. This in contrast to foreseen revision in the case of loosening, periprosthetic fractures and infections. The literature describes a stem revison percentage ranging between 0.0 and $62.5 \%$ $[9,12,16,18,19]$. However, most studies regarding this subject comprise small cohorts.

The primary goal of our study was to evaluate the unforeseen revision rate in modular stems in revision procedures from anatomical (total or hemi) to reverse shoulder arthroplasty in The Netherlands. Based on previous studies we hypothesized that a considerable number of convertible stems inserted in primary shoulder arthroplasty are not retained during revision arthroplasty, due to unforeseen circumstances. Secondly, we compared overall survival rates of the stem between shoulder arthroplasties (both the complete prosthesis and the stem separately) comprising a modular stem, and those comprising a non-convertible stem. Thirdly, we aimed to identify factors associated with stem revision.

\section{Methods}

For this cohort study, we retrospectively reviewed the Dutch Arthroplasty Register (LROI) database containing all shoulder arthroplasties performed between January 2014 and December 2016. The LROI is a nationwide registry for joint prostheses established by the Dutch Orthopaedic Association (NOV) in 2007 with over 100 affiliated institutes. Registration of shoulder arthroplasties started in January 2014. In 2016 94\% of primary arthroplasties and $92 \%$ of revision arthroplasties were registered in the database.

\section{Population}

We identified a total of 2834 registered primary arthroplasties. The registry supplied a list of types and brands of shoulder prostheses, which were labelled either as convertible or non-convertible by two researchers (LT, OLH) (Supplemental file).

For some non-convertible designed prostheses an adaptor is developed to enable revision to reversed without the need for a stem revision. As these designs were not primarily designed for conversion to reverse shoulder arthroplasty they were defined as nonconvertible $(n=3)$. Stemless designs were excluded from this study. After exclusion of patients with unknown stem type due to missing data $(n=337)$, patients were divided into two cohorts: a convertible group $(n=1067)$ and a non-convertible group $(n=1430)$. Follow up was at least 1 year. The study flow is presented in Fig. 1.

\section{Data collection}

The registration included demographic patient information, diagnostic information, and procedural information about both the primary as well as, when applicable, the revision procedures. The registry provided all the data anonymously, therefore if the type of the revision procedure was unknown (revision to total, reversed shoulder arthroplasty or extraction) these patients were excluded.

\section{Outcome measures}

The primary outcome of this study was to evaluate the unforeseen revision rate of convertible stems used in revision of anatomical (total and hemi) shoulder arthroplasty to reversed shoulder arthroplasty. In some cases, stem revision can be foreseen preoperatively, i.e. prosthetic joint infection, stem loosening and periprosthetic fractures. This was done for purpose of comparison to the literature and to provide surgeons insight in the amount of unforeseen stem-revision in clinical practice $[3,9,18-20]$. A secondary analysis was performed to determine the overall stem revision rate including foreseen stem revisions. Secondary outcomes were: overall prosthesis and stem survival in the convertible and the non-convertible design.

\section{Statistics}

Statistical analysis was performed using SPSS (IBM SPSS Statistics for Windows, version 24.0 [IBM Corp., Armonk, N.Y., USA]). Descriptive statistics (mean, median, range) were applied to describe patient characteristics. Categorical variables were analysed using Chi-square tests, while continuous variables were analysed depending on their distribution. In case of a normal distribution, the two-sample independent $\mathrm{T}$-test was used. In case of continuous variables without a normal distribution or ordinal variables 


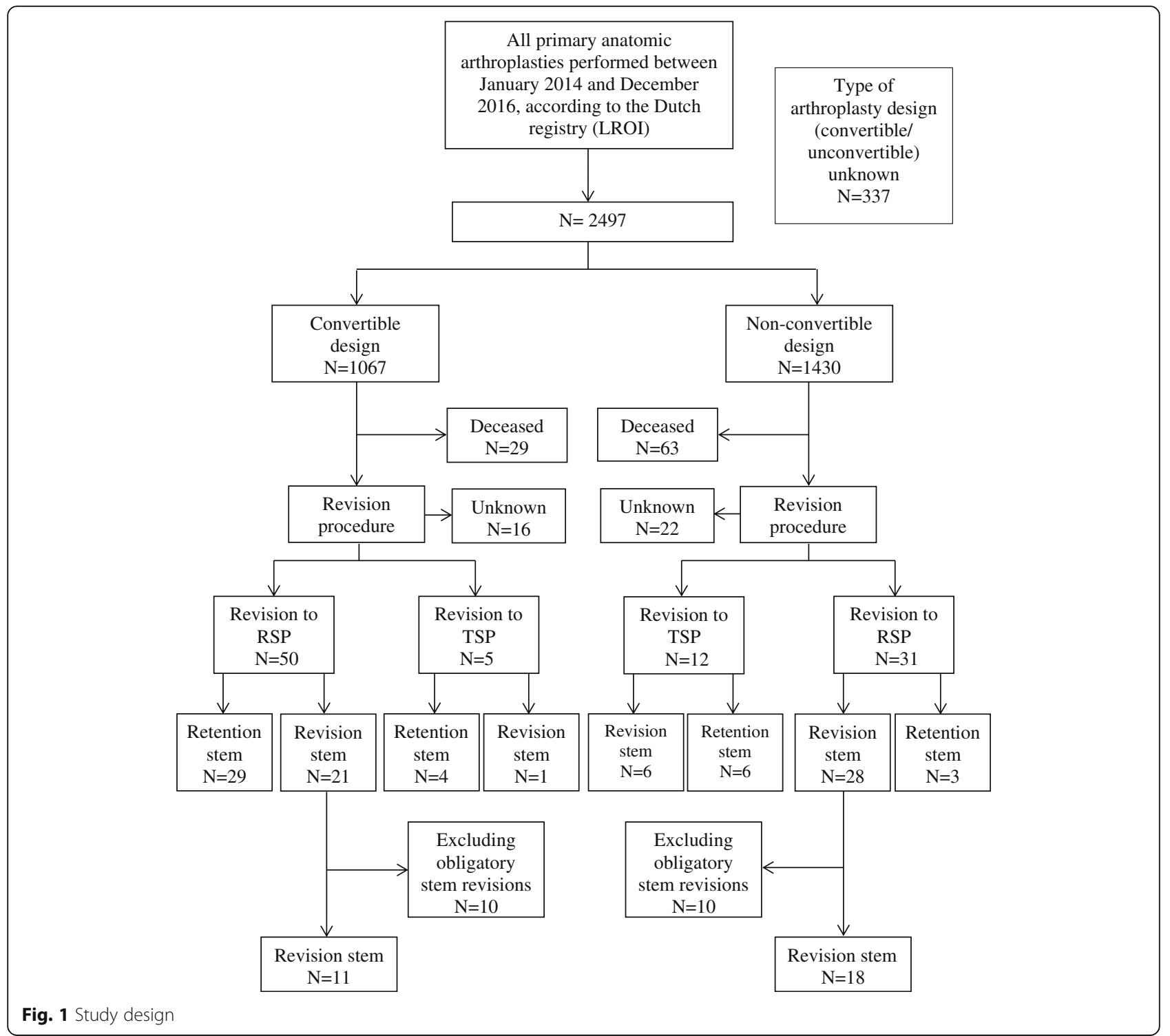

the Mann-Whitney test was used. Survival of the entire prosthesis, as well as survival of the humeral stem separately, were analysed by means of Kaplan-Meier analyses including the log rank test to compare convertible and non-convertible prostheses. Cox-regression survival analysis was used to calculate hazard ratios for the risk of stem revision and to correct for possible confounders. Independently, variables with a $p$-value $<0.1$ in a univariate Cox regression analysis were included in the multivariate analysis.

A $p$-value $<0.05$ was considered statistical significant. Missing values were not replaced.

\section{Results}

\section{Demographics}

Demographic patient characteristics are presented in Table 1 . The total cohort consisted of 2834 primary anatomic (total and hemi) shoulder arthroplasties (Fig. 1). A total of 2009 women (70.9\%) and 818 men (28.9\%) were included. Information on gender was missing in 7 patients $(0.2 \%)$. At the time of the primary procedure, the mean age was 66.3 years (SD 10.8) and mean follow-up was 2.4 years (SD 0.9). Overall implant survival was $94.5 \%$.

The convertible group consisted of 1067 patients with a mean age of 66.5 (SD 10.4) and the non-convertible group consisted of 1430 patients with a mean age of 66.9 (SD 10.7) at the time of the primary arthroplasty $(p=.39)$. Mean follow-up for the convertible design prostheses was 2.1 years (SD 0.84) and 2.5 years (SD $0.91)$ for the non-convertible prostheses $(p<0.01)$. Between 2014 and 2016 an increase of 28.6 to $53.7 \%$ was observed in the use of convertible stem designs $(p<0.01)$.

In 38 patients the type of revision was unknown and were therefore excluded from analysis. The distribution of anatomic total shoulder arthroplasties and hemiarthroplasties 
Table 1 Patient demographics of both the convertible stem group as well as the non-convertible stem group (SD: Standard deviation; ASA: American Society of Anesthesiologists classification)

\begin{tabular}{|c|c|c|c|}
\hline & Convertible stems $(n=1.067)$ & Non-convertible stems $(n=1.430)$ & $P$-value \\
\hline Age (years), Mean (SD) & $66.4(10.5)$ & $66.9(10.7)$ & 0.33 \\
\hline BMI $\left(\mathbf{k g} / \mathbf{m}^{2}\right)$, Mean, SD & $28.7(5.5)$ & $28.6(5.7)$ & 0.79 \\
\hline Sex, Male () & 26.9 & 28.5 & 0.37 \\
\hline Smoker, Yes (\%) & 17.1 & 14.5 & 0.08 \\
\hline ASA (\%) & & & 0.05 \\
\hline I & 11.9 & 14.5 & \\
\hline$\|$ & 67.6 & 63.1 & \\
\hline III-IV & 20.5 & 22.4 & \\
\hline Walch classification (\%) & & & 0.61 \\
\hline $\mathrm{A} 1 / \mathrm{A} 2$ & 80.7 & 79.6 & \\
\hline B1 & 13.7 & 13.9 & \\
\hline B2/B3 & 5.5 & 6.5 & \\
\hline Percentage/year (\%) & & & $<0.001$ \\
\hline 2014 & 28.6 & 71.4 & \\
\hline 2015 & 45.1 & 54.9 & \\
\hline 2016 & 53.7 & 46.3 & \\
\hline Side $(\%)$ & & & 0.79 \\
\hline Left & 47.1 & 47.7 & \\
\hline Right & 52.9 & 52.3 & \\
\hline \multicolumn{4}{|l|}{ Diagnosis (\%) } \\
\hline Osteoarthritis & 67.5 & 77.3 & $<0.001$ \\
\hline Fracture & 25.8 & 20.2 & \\
\hline Other & 6.8 & 2.4 & \\
\hline Approach (\%) & & & $<0.001$ \\
\hline Deltopectoral & 88.2 & 93.6 & \\
\hline Anterosuperior & 11.8 & 6.4 & \\
\hline Prosthesis type (\%) & & & 0.36 \\
\hline Hemi & 37.6 & 39.4 & \\
\hline Total & 62.4 & 60.6 & \\
\hline Fixation (\%) & & & $<0.001$ \\
\hline Cemented & 20.0 & 37.9 & \\
\hline Uncemented & 80.0 & 62.1 & \\
\hline Previous surgery, No (\%) & 86.8 & 88.0 & 0.37 \\
\hline
\end{tabular}

used in the primary procedure did not differ significantly between the convertible (total: 62.4\%; hemi: $37.6 \%$ ) and the non-convertible group (total: 60.6\%; hemi: $39.4 \%)(p=$ $0.40)$. The initial diagnosis for the arthroplasty procedure was osteoarthritis in the majority of patients in both groups: $67.5 \%$ versus $77.3 \%$ in the convertible and non-convertible group, respectively, followed by fractures ( $25.8 \%$ vs $20.2 \%)$. Significant differences were found in surgical approach (deltopectoral vs. anterosuperior) with more anterosuperior approach in the convertible group (11.4 vs. 6.7\%) $(p<0.01)$. Also, type of fixation (cemented vs. uncemented) varied significantly in both groups. In the convertible group $80 \%$ of the stems were uncemented, compared to $62.1 \%$ in the non-convertible group $(p<0.01)$.

\section{Primary outcome}

Unforeseen stem revision to reversed shoulder prosthesis In the convertible group, in 16 patients it was unknown if the revision was to a reverse or anatomical type arthroplasty or a extraction was performed. Fifty revisions concerned conversion to a reversed shoulder 
prostheses. In comparison, within the non-convertible group in 22 patients the type of revision surgery was unknown. Thirty-one revisions concerned conversion to a reversed shoulder prostheses. In the convertible group, the stem was retained in 29 out of 50 patients (58.0\%).

Ten cases in the convertible group were marked as obligatory stem revisions (cause of revision: stem loosening, periprosthetic infection). Excluding the foreseen revisions, the stem was retained in 29 of 40 revision procedures, leading to a stem retention percentage of $72.5 \%$.

\section{Secondary outcomes}

Overall prosthesis survival Seventy-one of the 1067 (6.7\%) convertible prostheses placed, required a revision procedure compared to 65 of $1430(4.5 \%)$ of the nonconvertible prostheses $(p=.02)$ (Fig. 1). The higher revision rate for convertible prostheses was confirmed by the Kaplan Meier analysis, showing lower survival for convertible prostheses compared to non-convertible prostheses $(p<0.01)$ (Fig. 2a). However, after correction for confounders (age, smoking status, Walch classification, diagnosis, prosthesis type, previous surgery), the difference in overall prosthesis survival between convertible and non-convertible prostheses disappeared (HR 1.36; 95\% CI 0.93-2.00). A lower age, a fracture as primary indication for surgery, a hemi shoulder arthroplasty and previous shoulder surgery all independently increased the risk of revision $(p<0.05)$ (Table 2).

\section{Overall survival of the stem}

The results of overall survival analyses of the stem revealed that in 28 of the 1067 (2.6\%) convertible arthroplasties placed a revision of the humeral stem was required, versus 43 of the $1430(3.0 \%)$ of the nonconvertible prostheses $(p=0.6)$. In the non-convertible group revision of the stem was not required in case of: glenoid revision, usage of an adapter or humeral head revision. The corresponding Kaplan-Meier survival graph is shown in Fig. 2b. Due to the crossing survival curves a log rank test was not indicated. After correction for possible confounders, survival of the humeral stem remained similar for convertible vs non-convertible designs (HR 0.8; 95\% CI 0.5-1.5).

Risk factors for survival of the entire prosthesis as well as survival of the humeral stem, are depicted in Table 2. A hemi shoulder arthroplasty and a previous shoulder surgery were both found to independently increase the risk of humeral stem revision (HR 2; 95\% CI 1.2-3.4 and HR 3.8; 95\% CI 2.3-6.6, respectively).

Outliers regarding revisions of certain brands of arthroplasties were not identified. In the convertible group 13 subtypes of prostheses were revised in 28 cases and in the non-convertible group 23 subtypes were revised in 43 revisions.

\section{Discussion}

The primary goal of this study was to evaluate the revision rate of convertible stems used in revision of anatomical (total and hemi) shoulder arthroplasty to reversed shoulder arthroplasty. The amount of unforeseen stem-revision (excluding the periprosthetic joint infections and stem loosening) in these revisions from anatomic/hemi to reverse was $27.5 \%$. In total, including the obligatory stem revisions the stem was revised in 42.0\%. After correction for confounders no significant differences were observed in overall prosthesis survival and stem survival between both groups. Overall implant survival was $94.5 \%$ after a mean follow-up of 2.4 years. No outliers were found regarding revision of certain brands of prostheses.

In our registry study in $27.5 \%$ an unforeseen stem revision was performed, in $72.5 \%$ of the revision to reversed procedures the convertible stem was retained. Previous studies on the topic of convertible humeral stem revisions revealed comparable stem retention rates ranging from $65.3-78.0 \%[3,9,18-20]$. In these studies patients with periprosthetic joint infections and stem loosening were excluded as in these indications stem revision is obligatory. Dilisio et al. reported a retention rate of $37.5 \%$, however revisions such as periprosthetic joint infections, loosening were included in this series, explaining the lower stem retention rate compared with other studies [16].

Due to the fact that we received anonymous registry data, case specific information regarding why the stem was revised was missing and could not be retrieved. A too minimal humeral head resection in the primary procedure may lead to a too proud position of the humeral stem which can put the cuff under stress and can result in cuff failure. Revision of these cases with malpositioning of the stem are at high risk of excessive tissue tensioning. Most common reasons for stem revision in the convertible group in literature are excessive tissue tensioning that makes the reduction of the reverse shoulder arthroplasty impossible or causes limited range of motion [6, 10, 19]. Surgeons should be aware that not all revisions in the convertible group are simple revisions. Excluding patients with stem loosening and periprosthetic joint infections in $27.5 \% \%$ of patients still a stem revision needs to be performed. One should be prepared to perform total revision arthroplasty.

After correcting for confounders we found no significant difference in survival rate between both groups. However, we found a significant rise in the use of convertible stem designs. A possible explanation for this finding is that revision surgery in convertible shoulder arthroplasty yields less complications and is less time consuming [6, 12-19]. 

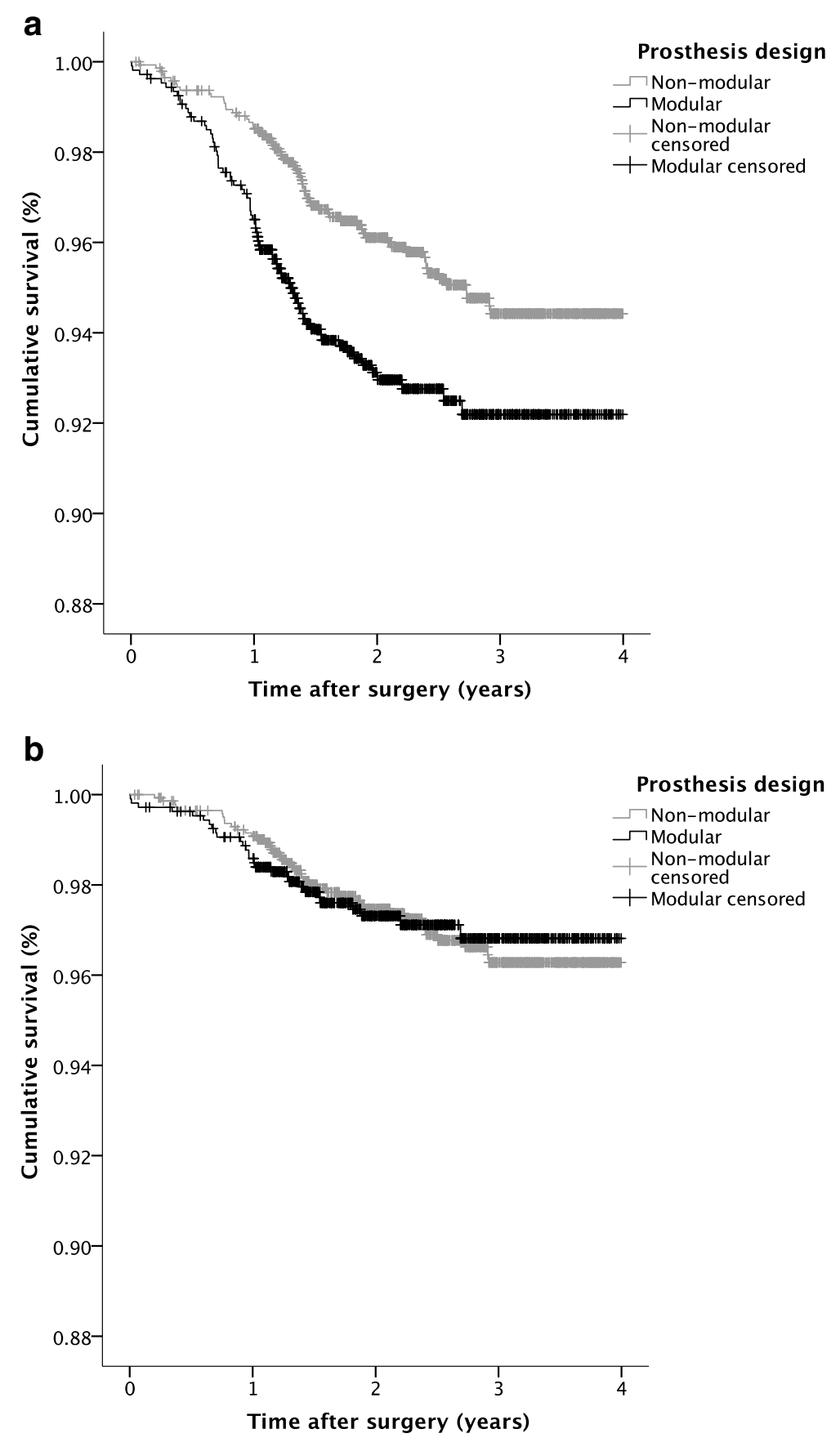

Fig. 2 Kaplan Meier Survival plots comparing survival in the convertible vs the non-convertible group. Plot (a) depicts survival of the entire prosthesis, whereas plot (b) depicts survival of the humeral stem

Despite this advantage we did not find an increased revision percentage of the convertible stems compared to the non-convertible stems. However, in the convertible group 9\% (5/55) of anatomical or hemi arthroplasties were revisions to a total or hemi shoulder arthroplasty, as in the non-convertible group this was the case in $28 \%$ $(12 / 43)$. This might be a reflection of the greater morbidity required to remove a well fixed stem. As this is a registry study we don't have case specific information to confirm the hypothesis.

The overall survival reported in the LROI was $94.6 \%$. The New Zealand registry showed a 2-year survival of 96.6\% [21]. Five-year survival percentages vary between 94.4-98.9\% [21-23]. In our study, the convertible group consisted of $37.6 \%$ hemiarthroplasties vs $39.4 \%$ in the non-convertible group. Our findings have shown that 
Table 2 Univariate and multivariate cox regression analyses for overall prosthesis survival and for survival of the stem separately. (HR: hazard ratio; ASA: American Society of Anesthesiologists classification)

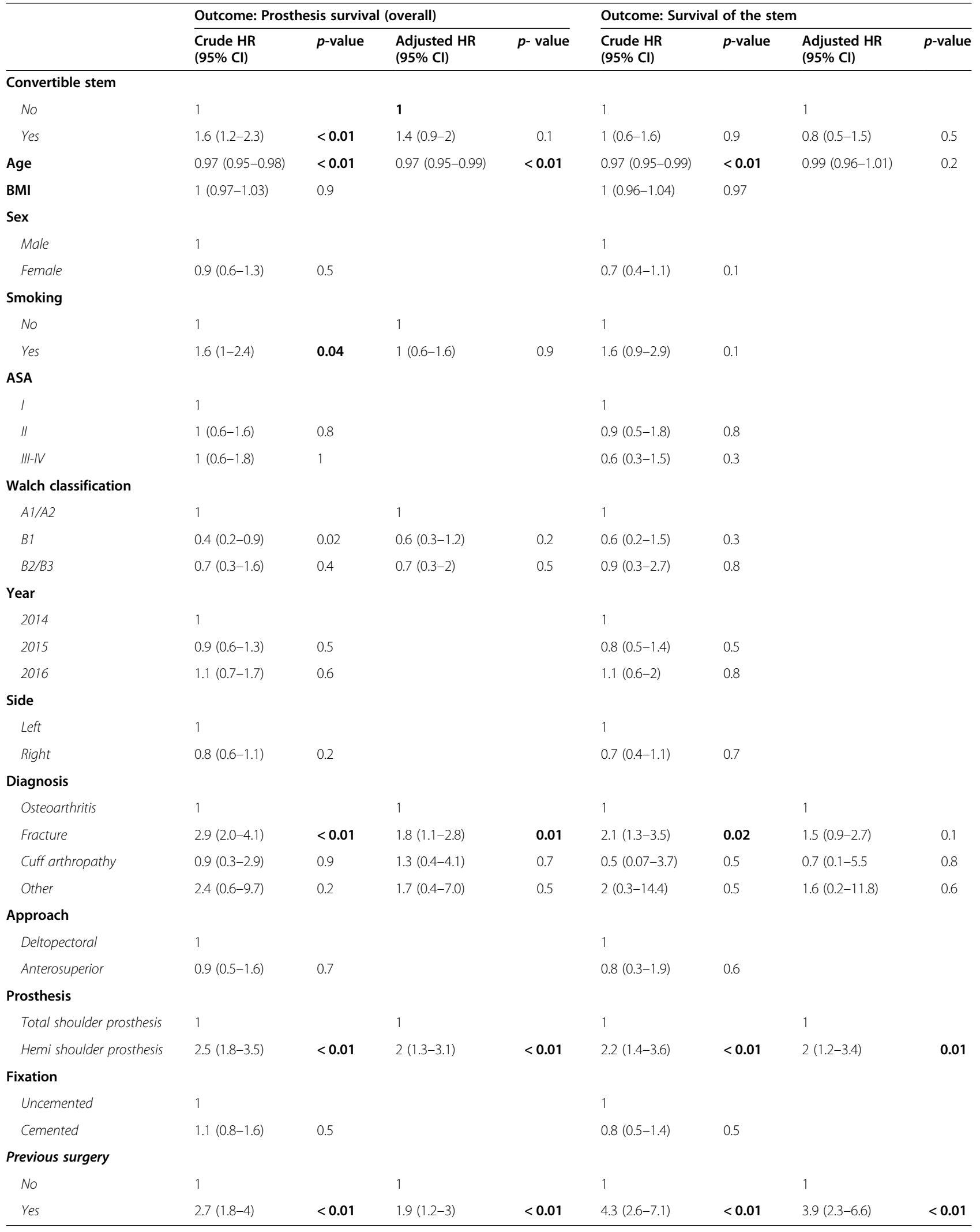


previous shoulder surgery, fracture as indication, lower age and hemiarthroplasty were risk factors for revision after multivariate cox regression analysis. Consequently, the high percentage of hemiarthroplasties in our cohort might explain the higher revision rate compared to literature.

A major strength of this study was that the cohort included a large number of patients. By using the LROI, a nationwide orthopaedic implantation registry, we created a large study group treated in all centres throughout The Netherlands. Furthermore, the LROI reported a completeness of data collection of $94 \%$ of primary procedures and $92 \%$ of revision procedures.

The LROI started collecting data of shoulder arthroplasties in 2014, which made the mean follow-up time of 2.4 years relatively short. Sixteen patients were excluded from the stem retention rate analysis due to missing data. In these patients it was not clear if they were revised to anatomical/ hemi, reverse shoulder arthroplasty or an extraction was performed. This may have resulted in a selection bias leading to an over or under estimation of the actual retention rate. As the data was anonymized the reason and type of revision could not be determined.

As part of a registry study the findings are based on a heterogenic group of patients, treated by many different surgeons, using many different designs for several indications. As a consequence, our findings are representative for the population as a whole, but are less applicable to specific designs.

\section{Conclusion}

Recently, there has been a profound rise in use of convertible shoulder arthroplasty among Dutch shoulder surgeons. It is assumed that revision of a convertible stem is less time consuming and yields less complications compared to removal of a well fixed stem. In approximately $72.5 \%$ of the unforeseen revision from anatomical / hemi to reversed arthroplasty the convertible stem could be retained. Surgeons and patients should be well informed that in $27.5 \%$ of patients the stem need to be revised.

\section{Abbreviations}

HR: Hazard ratio; LROI: Dutch Arthroplasty Register; NOV: Dutch Orthopaedic Association: SD: Standard deviation

\section{Supplementary Information}

The online version contains supplementary material available at https://doi. org/10.1186/s12891-021-04247-z

Additional file 1. Classification of convertible and non-convertible prostheses.

\section{Guarantor}

OLH.

Authors' contributions

$\mathrm{LT}$ and BM took the lead in writing the manuscript. $L J$ and BM analysed the data. AS-S, LJ, SV and OLH provided critical feedback and contributed to shape the research and manuscript. All authors reviewed and edited the manuscript and approved the final version of the manuscript.

\section{Funding}

This research received no specific grant from any funding agency in the public, commercial, or not-for-profit sectors.

\section{Availability of data and materials}

The datasets used and/or analysed during the current study are available from the corresponding author on reasonable request.

\section{Declarations}

\section{Ethics approval and consent to participate}

Ethical approval was not obtained for this study. According to the Central Committee on Research involving Human Subjects (CCMO), this type of study does not require approval from an ethics committee in the Netherlands. Informed consent was not sought for the present study. According to the Central Committee on Research involving Human Subjects (CCMO), informed consent from the study populations is not required for registry linkage studies.

\section{Consent for publication}

Not applicable.

\section{Competing interests}

The Authors declare that there is no conflict of interest.

\section{Author details}

${ }^{1}$ Department of Orthopaedic Surgery, VieCuri Medical Center, Venlo, The Netherlands. ${ }^{2}$ Dutch Arthroplasty Register (Landelijke Registratie Orthopedische Implantaten), 's Hertogenbosch, The Netherlands.

Received: 22 June 2020 Accepted: 12 April 2021

Published online: 28 April 2021

\section{References}

1. Day JS, Lau E, Ong KL, Williams GR, Ramsey ML, Kurtz SM. Prevalence and projections of total shoulder and elbow arthroplasty in the United States to 2015. J Shoulder Elb Surg. 2010;19(8):1115-20. https://doi.org/10.1016/j.jse.2 010.02.009.

2. Khatib O, Onyekwelu I, Yu S, Zuckerman JD. Shoulder arthroplasty in New York state, 1991 to 2010: changing patterns of utilization. J Shoulder Elb Surg. 2015;24(10):e286-91. https://doi.org/10.1016/j.jse.2015.05.038.

3. Kirsch JM, Khan M, Thornley P, Gichuru M, Freehill MT, Neviaser A, et al. Platform shoulder arthroplasty: a systematic review. J Shoulder Elb Surg. 2017;27(4):756-63. https://doi.org/10.1016/j.jse.2017.08.020.

4. Padegimas EM, Maltenfort M, Lazarus MD, Ramsey ML, Williams GR, Namdari S. Future patient demand for shoulder arthroplasty by younger patients: national projections. Clin Orthop Relat Res. 2015;473(6):1860-7. https://doi. org/10.1007/s11999-015-4231-z

5. Walch G, Boileau P, Noël E. Shoulder arthroplasty: evolving techniques and indications. Joint Bone Spine. 2010;77(6):501-5. https://doi.org/10.1016/j. jbspin.2010.09.004.

6. Werner BC, Dines JS, Dines DM. Platform systems in shoulder arthroplasty. Curr Rev Musculoskelet Med. 2016;9(1):49-53. https://doi.org/10.1007/s121 78-016-9317-z

7. Website. Australian Orthopaedic Association. Australian Orthopaedic Association National Joint Replacement Registry (AOANJRR) (2016). Adelaide. https://aoanjrr.sahmri.com/

8. Cil A, Veillette CJ, Sanchez-Sotelo J, et al. Revision of the humeral component for aseptic loosening in arthroplasty of the shoulder. J Bone Joint Surg Br. 2009:91(1):75-81. https://doi.org/10.1302/0301-620X. 91B1.21094. 
9. Cisneros $L G$, Atoun E, Abraham R, et al. Revision shoulder arthroplasty: does the stem really matter? J Shoulder Elb Surg. 2016;25(5):747-55. https://doi. org/10.1016/j.jse.2015.10.007.

10. Flury MP, Frey P, Goldhahn J, Schwyzer HK, Simmen BR. Reverse shoulder arthroplasty as a salvage procedure for failed conventional shoulder replacement due to cuff failure - midterm results. Int Orthop. 2011;35(1):5360. https://doi.org/10.1007/s00264-010-0990-z.

11. Sperling JW, Cofield RH. Humeral windows in revision shoulder arthroplasty. J Shoulder Elb Surg. 2005;14(3):258-63. https://doi.org/10.1 016/j.jse.2004.09.004.

12. Weber-Spickschen TS, Alfke D, Agneskirchner JD. The use of a modular system to convert an anatomical total shoulder arthroplasty to a reverse shoulder arthroplasty: clinical and radiological results. Bone Joint J. 2015;97B(12):1662-7. https://doi.org/10.1302/0301-620X.97B12.35176.

13. Cain MT, Crosby LA. A "convertible" humeral stem: a step forward in revision of total shoulder arthroplasty. Semin Arthroplast. 2016;27(2):108-11. https://doi.org/10.1053/.jsart.2016.08.004.

14. Castagna A, Delcogliano M, de Caro F, Ziveri G, Borroni M, Gumina S, et al. Conversion of shoulder arthroplasty to reverse implants: clinical and radiological results using a modular system. Int Orthop. 2013;37(7):1297305. https://doi.org/10.1007/s00264-013-1907-4.

15. Crosby LA, Wright TW, Yu S, Zuckerman JD. Conversion to reverse Total shoulder arthroplasty with and without humeral stem retention: the role of a convertible-platform stem. J Bone Joint Surg Am. 2017;99(9):736-42. https://doi.org/10.2106/JBJS.16.00683.

16. Dilisio MF, Miller LR, Siegel EJ, Higgins LD. Conversion to reverse shoulder arthroplasty: humeral stem retention versus revision. Orthopedics. 2015; 38(9):e773-9. https://doi.org/10.3928/01477447-20150902-54.

17. Merolla G, Wagner E, Sperling JW, Paladini P, Fabbri E, Porcellini G. Revision of failed shoulder hemiarthroplasty to reverse total arthroplasty: analysis of 157 revision implants. J Shoulder Elb Surg. 2018;27(1):75-81. https://doi. org/10.1016/j.jse.2017.06.038.

18. Wieser K, Borbas P, Ek ET, Meyer DC, Gerber C. Conversion of stemmed hemi- or total to reverse total shoulder arthroplasty: advantages of a modular stem design. Clin Orthop Relat Res. 2015;473(2):651-60. https://doi. org/10.1007/s11999-014-3985-z.

19. Williams PN, Trehan SK, Tsouris N, Dines JS, Dines DM, Craig EV, et al. Functional outcomes of modular conversion of hemiarthroplasty or total to reverse total shoulder arthroplasty. HSS J. 2017;13(2):102-7. https://doi.org/1 0.1007/s11420-017-9546-8

20. Singh JA, Sperling JW, Cofield RH. Revision surgery following total shoulder arthroplasty: analysis of 2,588 shoulders over 3 decades (1976-2008). J Bone Joint Surg Br. 2011;93(11):1513-7.

21. Website. New Zealand Orthopaedic Association (NZOA). The new zealand joint registry. Seventeen year report. Wellington: NZOA; 2016. https://nzoa. org.nz/system/files/NZJR\%2017\%20year20Report.pdf

22. Lorbach $\mathrm{O}$. Anatomische Schulterprothese bei Omarthrose, Indikation, aktuelle Implantate, klinische Ergebnisse. Orthopäde. 2018;47(5):383-9. https://doi.org/10.1007/s00132-018-3544-5.

23. Werthel JD, Lonjon G, Jo S, Cofield R, Sperling JW, Elhassan BT. Longterm outcomes of cemented versus cementless humeral components in arthroplasty of the shoulder: a propensity score-matched analysis. Bone Joint J. 2017;99-B(5):666-7. https://doi.org/10.1302/0301-620X.99B5.BJJ-2 016-0910.R1.

\section{Publisher's Note}

Springer Nature remains neutral with regard to jurisdictional claims in published maps and institutional affiliations.

Ready to submit your research? Choose BMC and benefit from:

- fast, convenient online submission

- thorough peer review by experienced researchers in your field

- rapid publication on acceptance

- support for research data, including large and complex data types

- gold Open Access which fosters wider collaboration and increased citations

- maximum visibility for your research: over $100 \mathrm{M}$ website views per year

At BMC, research is always in progress.

Learn more biomedcentral.com/submissions 